Article

\title{
Luteolin-Loaded Elastic Liposomes for Transdermal Delivery to Control Breast Cancer: In Vitro and Ex Vivo Evaluations
}

\author{
Mohammad A. Altamimi ${ }^{1, *(\mathbb{D})}$, Afzal Hussain ${ }^{1, * \mathbb{D}}$, Mohammad AlRajhi ${ }^{1}$, Sultan Alshehri ${ }^{1}$ (D), \\ Syed Sarim Imam ${ }^{1}$ (D) and Wajhul Qamar ${ }^{2}$
}

1 Department of Pharmaceutics, College of Pharmacy, King Saud University, P.O. Box 2457, Riyadh 11451, Saudi Arabia; 436107433@ksu.edu.sa (M.A.); salshehri1@ksu.edu.sa (S.A.); simam@ksu.edu.sa (S.S.I.)

2 Department of Pharmacology and Toxicology, College of Pharmacy, King Saud University, P.O. Box 2457, Riyadh 11451, Saudi Arabia; wqidris@ksu.edu.sa

* Correspondence: maltamimi@ksu.edu.sa (M.A.A.); amohammed2@ksu.edu.sa (A.H.)

Citation: Altamimi, M.A.; Hussain, A.; AlRajhi, M.; Alshehri, S.; Imam, S.S.; Qamar, W. Luteolin-Loaded Elastic Liposomes for Transdermal Delivery to Control Breast Cancer: In Vitro and Ex Vivo Evaluations. Pharmaceuticals 2021, 14, 1143. https://doi.org/10.3390/ph14111143

Academic Editor: Dimitris Tsiourvas

Received: 19 October 2021

Accepted: 8 November 2021

Published: 11 November 2021

Publisher's Note: MDPI stays neutral with regard to jurisdictional claims in published maps and institutional affiliations.

Copyright: (C) 2021 by the authors. Licensee MDPI, Basel, Switzerland. This article is an open access article distributed under the terms and conditions of the Creative Commons Attribution (CC BY) license (https:/ / creativecommons.org/licenses/by/ $4.0 /)$.

\begin{abstract}
The study aimed to prepare and optimize luteolin (LUT)-loaded transdermal elastic liposomes (LEL1-LEL12), followed by in vitro and ex vivo evaluations of their ability to control breast cancer. Various surfactants (Span 60, Span 80, and Brij 35), and phosphatidyl choline (PC) as a lipid, were used to tailor various formulation as dictated by "Design Expert ${ }^{\circledR}$ software (DOE). These were characterized for size, polydispersity index (PDI), and zeta potential. The optimized formulation (OLEL1) was selected for comparative investigations (in vitro and ex vivo) against lipo (conventional liposomes) and drug suspension (DS). Moreover, the in vitro anticancer activity of OLEL1 was compared against a control using MCF-7 cell lines. Preliminary selection of the suitable PC: surfactant ratio for formulations F1-F9 showed relative advantages of Span 80. DOE suggested two block factorial designs with four center points to identify the design space and significant factors. OLEL1 was the most robust with high functional desirability (0.95), minimum size (202 nm), relatively high drug release, increased drug entrapment $(92 \%)$, and improved permeation rate $\left(\sim 3270 \mu \mathrm{g} / \mathrm{cm}^{2}\right)$ as compared with liposomes $\left(\sim 1536 \mu \mathrm{g} / \mathrm{cm}^{2}\right)$ over $24 \mathrm{~h}$. OLEL1 exhibited a 6.2- to 2.9-fold increase in permeation rate as compared with DS (drug solution). The permeation flux values of OLEL1, and lipo were found to be 136.3, 64 and $24.3 \mu \mathrm{g} / \mathrm{h} / \mathrm{cm}^{2}$, respectively. The drug disposition values were $670 \mu \mathrm{g}$, $473 \mu \mathrm{g}$ and $148 \mu \mathrm{g}$, for OLEL1, lipo and DS, respectively. Thus, ex vivo parameters were significantly better for OLEL1 compared with lipo and DS which is attributed to the flexibility and deformability of the optimized formulation. Furthermore, OLEL1 was evaluated for anticancer activity and showed maximized inhibition as compared with DS. Thus, elastic liposomes may be a promising approach for improved transdermal delivery of luteolin, as well as enhancing its therapeutic efficacy in controlling breast cancer.
\end{abstract}

Keywords: luteolin; elastic liposomes; design expert-based optimization; ex vivo permeation and drug deposition; cytotoxicity against MCF-7

\section{Introduction}

Cancer is a disease with the highest mortality rate second only to cardiovascular disorders [1,2]. Furthermore, Sung H, et al., published statistics based on GLOBOCAN, showing that nearly 20 million new cancer cases and 10 million deaths occurred worldwide in the year 2020 alone. The projection of newly diagnosed cancer cases worldwide is estimated to be nearly 30 million in 2040 [3]. In 2020, 2.3 million women were diagnosed with breast cancer and 568,000 deaths occurred globally [4].

Several synthetic and natural drugs have been explored for their therapeutic potential to control breast cancer. However, commercial synthetic or semi-synthetic drugs are associated with various side effects and drug related toxicity. Natural luteolin (LUT) is found in spinach, different peppers, and lettuce. LUT possess anticancer potential despite 
having various additional therapeutic benefits (antioxidant, anti-inflammatory, antiapoptotic agent). Chemically, the drug is a natural flavone (tetrahydroxy flavone) with four hydroxyl functional groups positioned at 3, 4, 5, and 6 of basic moiety and conjugate acid of 2-(3,4-dihydroxyphenyl)-5-hydroxy-4-oxo-4H-chromen-7-olate luteolin-7-olate(1-) (Figure 1A) [5,6]. Pharmacologically, the drug is a potential antioxidant (free radical scavenger), anti-inflammatory, anti-mutagen, antimicrobial, immunomodulatory, apoptosis inducer, and anti-neoplastic against several cancer types [7-10]. Pharmaceutically, lipophilic LUT $(\log P \sim 2.53)$ is poorly soluble in water $(0.0055 \mathrm{mg} / \mathrm{mL})$, unstable in gastric lumen due to acidic environment (pKa 6.5) and is associated with low oral bioavailability $(<30 \%)[11,12]$. Considering this context, it is a challenging task to formulate a suitable dosage formulation for oral and parenteral delivery due to poor aqueous solubility in water. Therefore, low molecular weight LUT $(286 \mathrm{~g} / \mathrm{mole})$ is a suitable drug candidate for transdermal delivery using vesicular nanocarrier to control breast cancer. Transdermal route of administration does overcome barriers as it avoids the first pass metabolism, has direct and local exposure, avoids stability issues related to gastric fluid, and offers improved patient compliance. However, percutaneous drug delivery faces the major challenge of low drug penetration. Topically applied medicines must pass through the stratum corneum (SC) which contain corneocytes in lipid matrix. Thus, the drug must pass through small pore sizes of nearly $30 \mathrm{~nm}$ [13]. Liposomes, elastic liposomes, ethosomes, niosomes, and PEGylated liposomes have been explored as several lipophilic compounds for transdermal and topical administration. Abidin et al. investigated enhanced transdermal delivery of LUT via non-ionic niosomes to control arthritis [14]. Similarly, Huang et al. encapsulated luteolin in liposomes and compared the protective effect of liposomes loading LUT, quercetin and kaempferol in term of structure, size, and loading [15]. However, elastic liposomes possess unique benefits over other vesicular systems due to their ultra-deformability, absence of cholesterol, and capability to permeate across microscopic pores of skin for drug access to the dermal region. Physicochemical properties of elastic vesicles depend upon several factors such as (a) the type of surfactant (ionic, non-ionic and amphiphilic), (b) nature of the hydrocarbon chain present in lipid and surfactant (saturated, unsaturated, branching and length), size of surfactant head group (polar, charged or uncharged), concentration, transition temperature of surfactant, and lipophilicity (lipid, surfactant, and drug) $[16,17]$. Thus, to our knowledge, no report has been published regarding the transdermal delivery of LUT for the treatment of breast cancer.

A<smiles>O=c1cc(-c2ccc(O)c(O)c2)oc2cc(O)cc(O)c12</smiles>

B<smiles>CCCCCCCCC=CCCCCCCC(=O)OCC(CCOP(=O)(O)OCC[N+](C)(C)C)OC(=O)CCCCCCCCC</smiles>

Figure 1. Chemical structures of (A) luteolin, and (B) phosphatidylcholine of Phospholipon 90G. 
In this study, we aimed to formulate LUT-loaded elastic liposomes using various surfactants (based on different HLB and transition temperature), optimize them using Design Expert, and evaluate their in vitro parameters. Ex vivo permeation parameters (cumulative permeation rate, enhancement ratio, permeation flux and drug deposition) were investigated using rat skin for comparison against the drug suspension. Finally, the optimized formulation was evaluated for in vitro anticancer activity using MCF-7 cell lines.

\section{Results and Discussion}

\subsection{Screening of Lipid and Surfactant Ratio}

\subsubsection{Preliminary Study to Select Lipid and Surfactant Ratio}

The basic liposomal formulation contains phospholipid (containing 94\% phosphatidylcholine as major constituent as shown in Figure 1B) and surfactant in a specific ratio. Here, formulations were prepared using varied ratios of phosphatidylcholine to surfactants. The selected composition ratios were (PC: Span 60, PC: Span 80 and PC: Brij 35) (Table 1). The basis for selection of the surfactants were hydrophilic lipophilic balance (HLB), which was anticipated to have significant impact on size, \% EE, and elastic nature of ELs. Results revealed significant difference in the values of size and PDI when formulated with the selected ratio of PC to specific surfactant based on HLB (low and high) and glass transition temperature (low to high) of surfactant as shown in Table 1. Nonionic Span 80 (HLB 4.3) and Span 60 (HLB 4.7) are expected to impart substantial deformability and flexibility in the lipid bilayer followed by reduced vesicle size and PDI values. Therefore, results showed reduced size of the vesicles (358-170 nm) and PDI (0.62-0.35) values. Also, the change in PDI values may be due to formation of small micelles to some extent $[16,18,19]$. On the other hand, nonionic (hydrophilic) polyoxyethylene (23) laurylether (Brij 35) with (HLB 16.9) showed an increase in the average vesicle size compared with the lipophilic surfactants with nearly similar PDI values at different ratios [20-22]. The disparity in the hydrophilicity between Brij 35 and LUT is attributed to the average larger vesicles size as compared with Span 60 and Span 80. In general, micelles are formed above their $\mathrm{CMC}$ value and can coexist with the liposomal formulation leading to reduced size and entrapment efficiency of the formulated vesicles. Therefore, Span 80 was selected as the suitable surfactant for further optimization using the experimental tool (two blocks factorial design with four center points) (Design Expert). In the present study, $30 \mathrm{mg}$ lutein was added to the formulation to get $3 \mathrm{mg}$ per $\mathrm{g}$ of total formulation $(0.3 \% \mathrm{w} / \mathrm{w})$. Moreover, the drug strength per $100 \mathrm{mg}$ of lipid was found to be in the range of 3.2-4.3 $\mathrm{mg}$ for the developed formulations (Table 1).

Table 1. A summary of preliminary formulations of elastic liposomes (F1-F9) using various types of surfactant and their characterization parameters.

\begin{tabular}{|c|c|c|c|c|c|c|}
\hline Code & PC:S $(\% w / w)$ & Surfactant & HLB & $\mathrm{T}_{\mathrm{g}}\left({ }^{\circ} \mathrm{C}\right)$ & Vesicle Size (nm) & PDI \\
\hline F1 & $95: 5 *$ & Span 60 & 4.7 & 53 & $358 \pm 16$ & $0.62 \pm 0.05$ \\
\hline F2 & $85: 15$ & Span 60 & 4.7 & 53 & $284 \pm 13$ & $0.44 \pm 0.03$ \\
\hline F3 & $70: 30$ & Span 60 & 4.7 & 53 & $187 \pm 11$ & $0.43 \pm 0.02$ \\
\hline F4 & $95: 5 *$ & Span 80 & 4.3 & -12 & $218 \pm 9$ & $0.45 \pm 0.03$ \\
\hline F5 & $85: 15$ & Span 80 & 4.3 & -12 & $212 \pm 9$ & $0.30 \pm 0.01$ \\
\hline F6 & $70: 30$ & Span 80 & 4.3 & -12 & $170 \pm 6$ & $0.35 \pm 0.02$ \\
\hline F7 & $95: 5 *$ & Brij 35 & 16.9 & $40-45$ & $385 \pm 8$ & $0.42 \pm 0.03$ \\
\hline F8 & $85: 15$ & Brij 35 & 16.9 & $40-45$ & $266 \pm 5$ & $0.35 \pm 0.02$ \\
\hline F9 & $70: 30$ & Brij 35 & 16.9 & $40-45$ & $234 \pm 6$ & $0.45 \pm 0.04$ \\
\hline
\end{tabular}

Value represented as mean \pm SD $(n=3)$, PC: $\mathrm{S}=$ phosphatidylcholine to surfactant ratio, HLB = hydrophilic lipophilic balance, $\mathrm{T}_{\mathrm{g}}=$ glass transition temperature. * The minimum concentration where surfactant can form micelles. Values are reported at $25^{\circ} \mathrm{C}$. PDI: Polydispersity index 


\subsubsection{Optimization Using Design Expert}

This experimental tool is used for identifying the relationships between independent factors and dependent factors. These processes involve identifying factors, their levels, and their importance. In addition, it can identify the interactions between factors (independent variables) against set responses (dependent variables), which for this study entailed two factors $\left(X_{1}\right.$ and $\left.X_{2}\right)$ at two levels such as minimum $(-1)$ and maximum $(+1)$. Independent (factors) and dependent variables (responses) were opted considering preliminary results of size and PDI values. Thus, PC $\left(X_{1}\right)$ and Span $80\left(X_{2}\right)$ were two independent factors against three responses, namely vesicle size $\left(\mathrm{Y}_{1}\right)$, zeta potential $\left(\mathrm{Y}_{2}\right)$, and \%EE $\left(\mathrm{Y}_{3}\right)$. Two runs at higher and lower levels were conducted to find the noise in each response and establish signal to noise ratios. This ratio allows for design power estimation where anything above $80 \%$ is deemed satisfactory. In brief, a two blocks factorial design was given by the system at different factor levels. Formulations were made accordingly with the drug as $30 \mathrm{mg} / 10 \mathrm{~g}$ of drug and the data was plotted in each response (see Table 2). The program generated a quadratic equation as $Y=b_{0}+b_{1} X_{1}+b_{2} X_{2}+b_{3} X_{1} X_{2}$ where $b_{0}, b_{1}, b_{2}, b_{3}$ and $X_{1} X_{2}$ are the intercept, linear-coefficients, and interaction term respectively, for the response $Y$ (Table 3 ).

Table 2. Independent variables $(X)$, responses $(Y)$ and statistical models for luteolin-loaded elastic liposomes in experimental design.

\begin{tabular}{llllllll}
\hline Std & Block & Run & $\begin{array}{l}\text { Factor 1 } \\
\mathbf{X}_{\mathbf{1}}: \mathbf{P C} \\
(\mathbf{m g})\end{array}$ & $\begin{array}{l}\text { Factor 2 } \\
\mathbf{X}_{\mathbf{2}}: \text { Span } \\
\mathbf{8 0}(\mathbf{m g})\end{array}$ & $\begin{array}{l}\text { Response 1 } \\
\text { Size (nm) }\end{array}$ & $\begin{array}{l}\text { Response 2 } \\
\text { Zeta (mV) }\end{array}$ & $\begin{array}{l}\text { Response 3 } \\
\text { EE (\%) }\end{array}$ \\
\hline 5 & Block 1 & 1 & 70 & 30 & 265 & 20.4 & 85.39 \\
9 & Block 1 & 2 & 82.5 & 17.5 & 739 & 25.3 & 57.82 \\
1 & Block 1 & 3 & 70 & 5 & 644 & 13.1 & 43.67 \\
10 & Block 1 & 4 & 82.5 & 17.5 & 738 & 22.9 & 64 \\
7 & Block 1 & 5 & 95 & 30 & 317 & 26.9 & 52.55 \\
3 & Block 1 & 6 & 95 & 5 & 871 & 27.2 & 47.53 \\
11 & Block 2 & 7 & 82.5 & 17.5 & 777 & 26.2 & 58.97 \\
2 & Block 2 & 8 & 70 & 5 & 657 & 15.3 & 46.13 \\
12 & Block 2 & 9 & 82.5 & 17.5 & 744 & 25 & 61.61 \\
8 & Block 2 & 10 & 95 & 30 & 365 & 24.8 & 48.52 \\
6 & Block 2 & 11 & 70 & 30 & 294 & 20 & 92.06 \\
4 & Block 2 & 12 & 95 & 5 & 810 & 24.9 & 51.57 \\
\hline
\end{tabular}

\subsubsection{Responses Evaluation}

Vesicle Size (nm): $Y_{1}$

The size of any elastic liposomal formulation is a critical parameter for developing formulations for topic use. The approached is established and validated for various drugs. However, elastic liposomes (ELs) have unique characteristics over conventional liposomes such as deformability, flexibility of the vesicle membrane, adaptability to stress, and sensitivity to the water gradient of skin [23,24]. This uniqueness allows for better squeezing through smaller skin pores. The vesicle size values of the proposed twelve runs and the polynomial quadratic equation for the response $Y_{1}$ are presented in Tables 2 and 3. Each term has either positive or negative signs indicating either a synergistic or antagonistic effect of the response $Y_{1}$. Particle size ranged between $265-871 \mathrm{~nm}$ and the quadratic equation was $Y_{1}=527.9+62.87 X_{1}-217.63 X_{2}-32.12 X_{1} X_{2}$. Figure $2 \mathrm{~A}$ illustrates the response surface plot of $Y_{1}$. The quadratic equation was the best fit model based on an analysis of variance (ANOVA) report and showed $p$ (0.0001), high value of $F(204.2)$ and $r^{2}$ value of 0.99 (Table 3). This mathematical model of the response $\left(Y_{1}\right)$ on factors $\left(X_{1}\right.$ and $\left.X_{2}\right)$ showed that the vesicle size significantly $(p<0.05)$ increases with a decrease in Span 80 content at any content of PC. However, the highest vesicle size was observed at highest level of $\left(X_{1}\right)$ and lowest level of $\left(X_{2}\right)$. The value of the adjusted regression coefficient $\left(r^{2}\right)(0.99)$ was in agreement with the predicted $\left(r^{2}\right)(0.95)$, suggesting a good model fit. 
Therefore, Y1 can be optimized by increasing Span 80 content and lowering PC content (size at minimum $\sim 265 \mathrm{~nm}$ ).

Table 3. Factors and responses and statistical parameters for luteolin-loaded elastic liposomes in experimental design.

\begin{tabular}{lll}
\hline & \multicolumn{2}{l}{ Experimental Design and Summary Reports } \\
\hline Factors & Range & Goal \\
\hline $\mathrm{X}_{1}: \mathrm{PC}(\mathrm{mg})$ & $70-95$ & In range \\
$\mathrm{X}_{2}:$ Span $80(\mathrm{mg})$ & $5-30$ & In range \\
\hline Responses & & \\
\hline $\mathrm{Y}_{1}(\mathrm{~nm})$ as size & $265-871$ & Minimum \\
$\mathrm{Y}_{2}(\mathrm{mV})$ as zeta potential & $-13.1-27.2$ & Maximum \\
$\mathrm{Y}_{3}(\%)$ as \% EE & $43.7-92.1$ & Maximum \\
\hline Regression equations with best fitted model & \\
\hline
\end{tabular}

\begin{tabular}{|c|c|c|c|}
\hline \multicolumn{4}{|c|}{ Regression equations with best fitted model } \\
\hline \multicolumn{4}{|c|}{$\begin{array}{l}\mathrm{Y}_{1}=527.9+62.87 \mathrm{X}_{1}-217.63 \mathrm{X}_{2}-32.12 \mathrm{X}_{1} \mathrm{X}_{2} \\
\mathrm{Y}_{2}=21.58+4.73 \mathrm{X}_{1}+1.45 \mathrm{X}_{2}-1.55 \mathrm{X}_{1} \mathrm{X}_{2} \\
\mathrm{Y}_{3}=58.43-8.39 \mathrm{X}_{1}+11.2 \mathrm{X}_{2}-10.71 \mathrm{X}_{1} \mathrm{X}_{2}\end{array}$} \\
\hline Statistical parameters & Y1 & Y2 & Y3 \\
\hline$r^{2}$ & 0.99 & 0.93 & 0.98 \\
\hline Adjusted $\mathrm{r}^{2}$ & 0.99 & 0.90 & 0.97 \\
\hline Predicted $\mathrm{r}^{2}$ & 0.95 & 0.72 & 0.90 \\
\hline Model f value & 204.16 & 28.69 & 83.67 \\
\hline$p$ value & 0.0001 & 0.0006 & 0.0001 \\
\hline Model & Quadratic & Quadratic & Quadratic \\
\hline SD & 26.15 & 1.48 & 3.14 \\
\hline Mean value & 601.75 & 22.67 & 59.15 \\
\hline$\% \mathrm{CV}$ & 4.35 & 6.54 & 5.32 \\
\hline
\end{tabular}

Value of regression coefficient represented as $\mathrm{r}^{2}, \mathrm{SD}=$ Standard deviation, $\% \mathrm{CV}=$ Coefficient of variation.

\section{Zeta Potential (ZP): $\mathrm{Y}_{2}$}

The electric potential difference in vesicle double layer and media is called Zeta potential. Higher ZP values (nearly $\pm 30 \mathrm{mV}$ ) represent a good stability in colloidal system [25]. The values of PC and Span 80 based on the design of experiment (12 runs) formulations showed in the range of -13 to $-27 \mathrm{mV}$. The quadratic equation was $\mathrm{Y}_{2}=21.58+4.73 \mathrm{X}_{1}+1.45 \mathrm{X}_{2}-1.55 \mathrm{X}_{1} \mathrm{X}_{2}$. Figure $2 \mathrm{~B}$ shows the response surface plot of $Y_{2}$. The quadratic model was the best fit and supported with ANOVA report $[p(0.0006)$, high F (28.7) and $\mathrm{r}^{2}$ values (0.93) (Table 3)]. This mathematical model of the response $\left(Y_{2}\right)$ on factors $\left(X_{1}\right.$ and $\left.X_{2}\right)$ showed that zeta potential significantly $(p<0.05)$ increases with increase in PC and Span 80 contents. The value of adjusted regression coefficient $\left(\mathrm{r}^{2}\right)$ $(0.90)$ and predicted $\left(r^{2}\right)(0.72)$ suggesting enough power for model fit. Here, values of zeta potential were found to be significantly higher with higher PC levels regardless of Span 80 content. However, the zeta potential decreased the most when both factors were at lower levels. 
$\mathbf{A}$

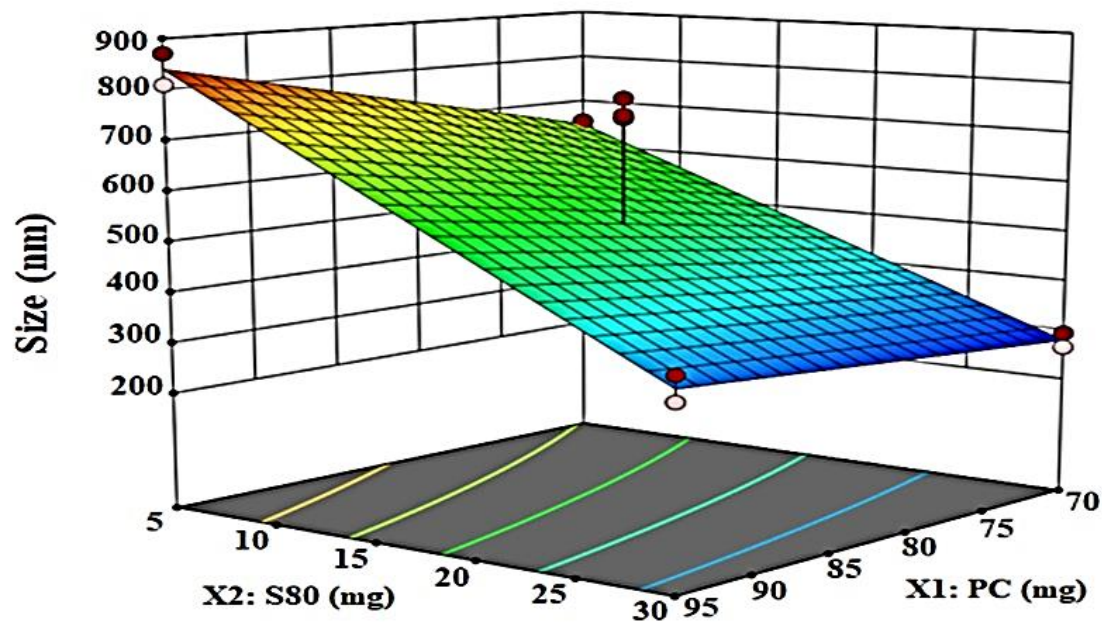

B

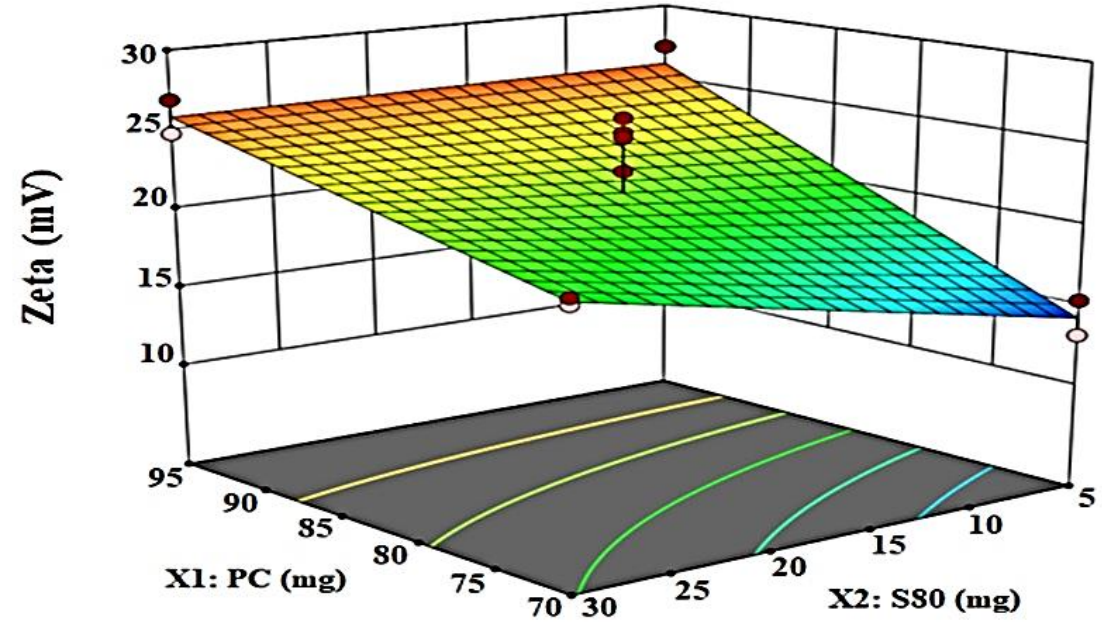

C

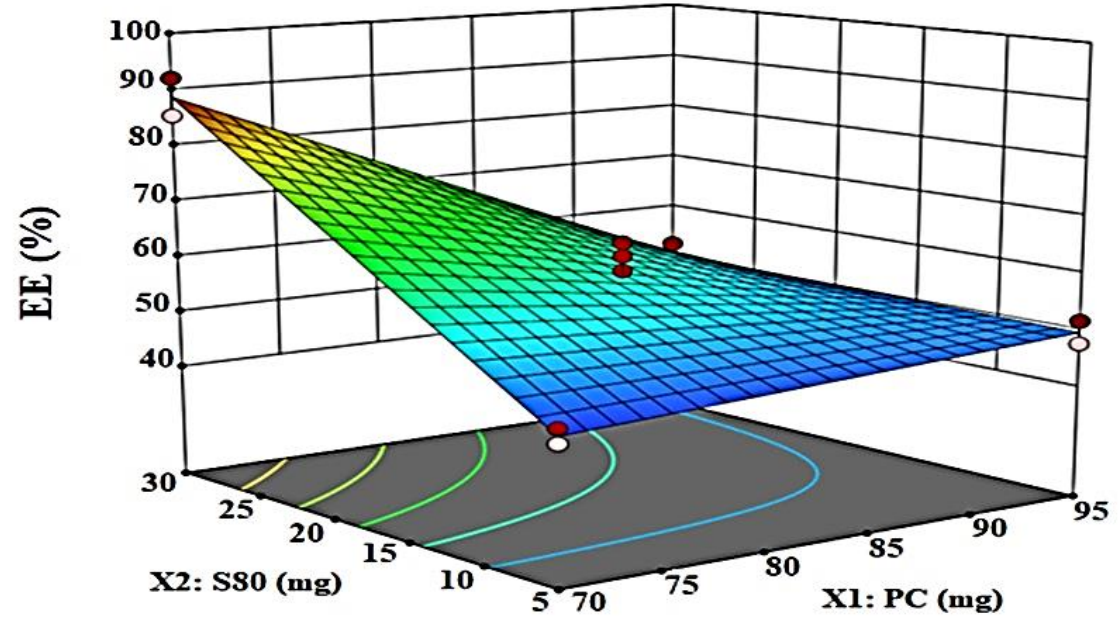

Figure 2. Design Experiment 3-dimensional response surface plots of the vesicle size $\left(\mathrm{Y}_{1}\right)$, zeta potential $\left(\mathrm{Y}_{2}\right)$, and \% EE $\left(\mathrm{Y}_{3}\right)$. (A) Three-dimensional response surface plot of $\left(\mathrm{Y}_{1}\right)$ depicting minimal change in size with increase in PC content at high surfactant level. However, the size increases with decrease in Span 80 content at any PC levels. (B) Three-dimensional response surface plot of $\left(\mathrm{Y}_{2}\right)$ depicting changes in zeta potential with change in PC and Span 80 levels. Here, the lowest value observed at low levels of both factors. (C) Three-dimensional response surface plot of $\left(\mathrm{Y}_{3}\right)$ which revealed a significant increase in the \% EE of LUT at lower level of PC and higher level of Span 80. 
Percentage Entrapment Efficiency: $\mathrm{Y}_{3}$

LUT is a hydrophobic drug with a $\log p$ of three. Thus, LUT is anticipated to be entrapped in the layer (lipid bilayer) ELs vesicles through lipophilic-lipophilic interaction. The percentage of entrapped LUT in the elastic liposomal formulation was found in the range of 43.7-92.1\% (Table 2). Here, the \%EE increased with an increase in Span 80 content which can be attributed to the flexibility that Span 80 added to the vesicles. Varshosaz et al. claimed that Span 80-containing niosomes exhibited a lower \%EE of insulin, indicating that LUT will be entrapped at a higher percentage within the lipophilic lipid bilayers of vesicles [26]. Generally, lower HLB-based surfactant is appropriate for high \% EE of hydrophobic drugs and vice versa. Thus, these effects are attributed to increased \%EE of LUT in elastic liposomes containing Span 80. A software generated the mathematical quadratic equation of $\mathrm{Y}_{3}=58.43-8.39 \mathrm{X}_{1}+11.2 \mathrm{X}_{2}-10.71 \mathrm{X}_{1} \mathrm{X}_{2}$, which established a relationship between the response (\%EE) and the independent variables $\left(X_{1}\right.$ and $\left.X_{2}\right)$ (Table 3). This generated equation for $Y_{3}$ is valid as evidenced by the statistical values of $p$ (0.0001) and $\mathrm{f}$ (83.67). Figure 2C depicts the 3-D surface plot of $\mathrm{Y}_{3}$ against $\mathrm{X}_{1}$ and $X_{2}$. ANOVA analysis report found a good agreement between the adjusted $r^{2}(0.97)$ and predicted $\mathrm{r}^{2}(0.90)$ indicating a good fit of the quadratic model for $\mathrm{Y}_{3}$. Thus, at lower content of $X_{1}$ and higher content of $X_{2}$, the maximum \%EE of LUT will be obtained. There were no significant interactions existing between the factors and responses as shown in Figure $3 \mathrm{~A}-\mathrm{C}$.

\subsubsection{Desirability}

This numerical objective function is applied for validation of the optimization process. Here, the optimized formulations is identified under a specific set of constraints and importance is given to the independent and dependent variables [27]. This function suggested four formulations with specific levels of $X_{1}$ and $X_{2}$. Experimental values of vesicle size, PDI, and \%EE for optimized formulation OLEL1 with desirability function values of 0.95 is observed as shown in Table 4 . The observed values were found to be in agreement with predicted values suggesting the best fit of the model. The overall desirability approached an approximate value (0.95) of unity which indicated the suitability of the model for the optimization process (Figure 4).

\subsubsection{Morphological Assessment}

The optimized elastic liposome OLEL1 was visualized under TEM for morphological study (Figure 5A). Here, the vesicles appeared to be spherical in shape, apparently dispersed, and uniformly distributed in the colloidal dispersion of elastic liposomes. Also, this showed that the colloidal suspension of elastic liposomes was stable without sign of phase separation and aggregation. Moreover, there were no drug precipitation in the colloidal suspension. It is clear in the image that the outer lipid bilayer is firm and stable, composed of the explored lipid and surfactant.

Table 4. Values of the predicted optimized and experimental formulations.

\begin{tabular}{lccccc}
\hline & PC & Span 80 & Size & Zeta & EE\% \\
\hline Predicted & 70 & 30 & 276 & 20.2 & 88.73 \\
\hline Experimental OLEL1 & 70 & 30 & 202 & 22.2 & $92 \pm 3.8$ \\
\hline
\end{tabular}


A

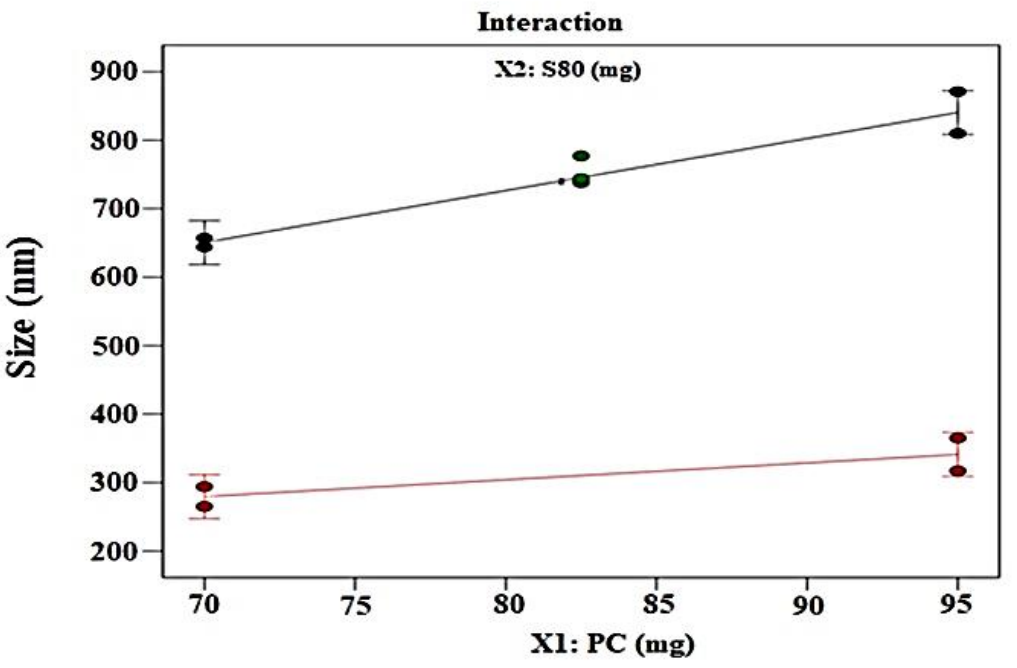

B

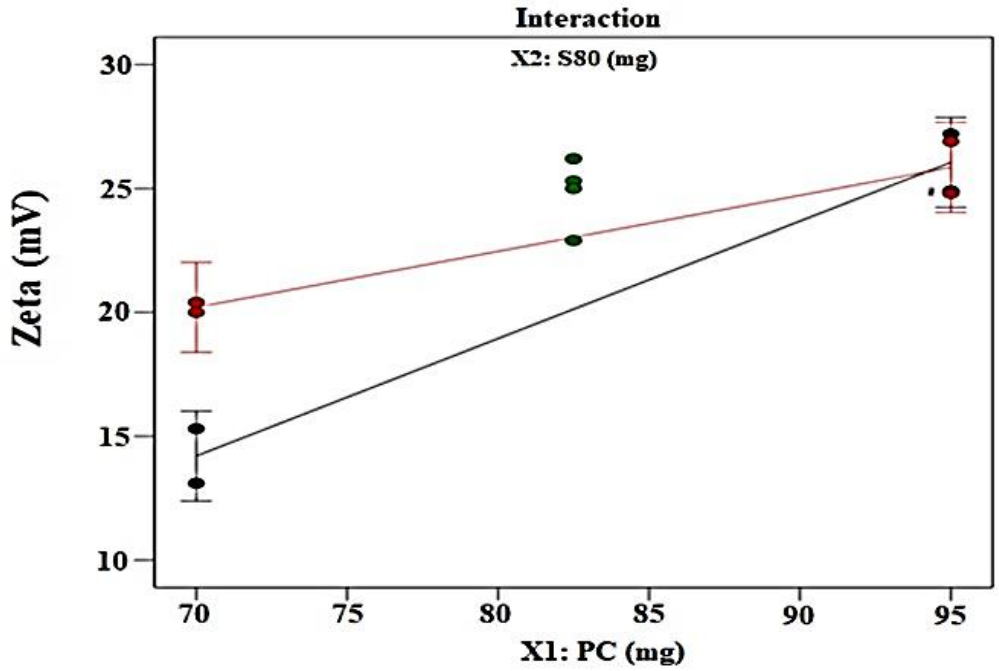

$\mathbf{C}$

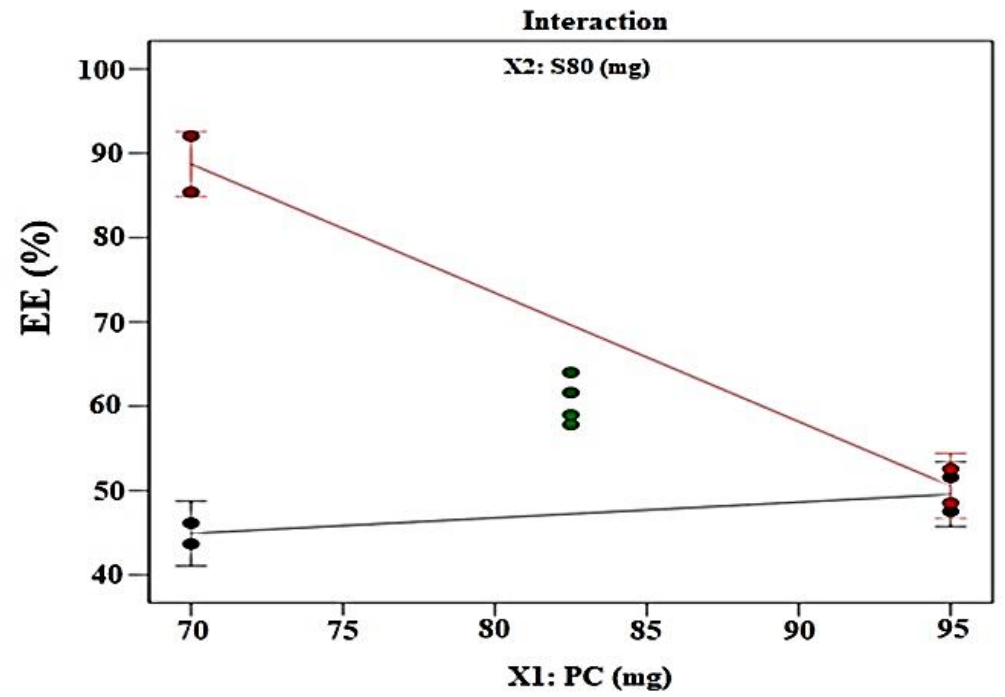

Figure 3. Design experiment factor interaction plots of $(\mathbf{a})$ the vesicle size $\left(\mathrm{Y}_{1}\right)$, (b) zeta potential $\left(\mathrm{Y}_{2}\right)$, and $(\mathbf{c}) \% \mathrm{EE}\left(\mathrm{Y}_{3}\right)$. Green dots represent center points. 


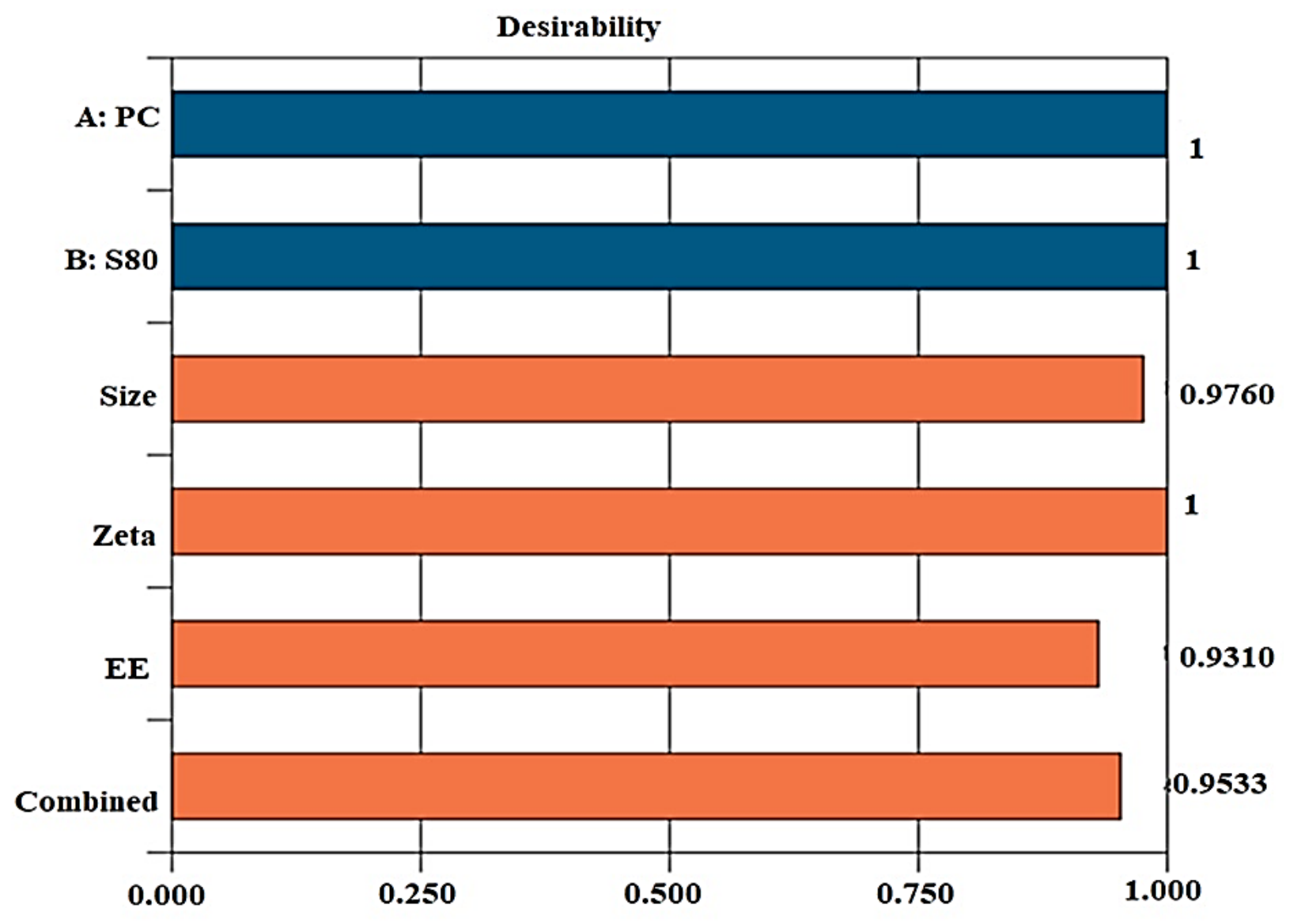

Solution 1 out of 4

Figure 4. The desirability function of the optimized proposed formulations (OLEL1).

\subsubsection{Elasticity}

The proposed vesicular carrier system is devoid of cholesterol and expected to bear maximized ultra-deformability under stress conditions. Therefore, it is expected to have relatively high flexibility due to the combined effect of plasticizer ( $7 \%$ ethanol), and Span 80 (serving as edge activator). Cholesterol provides a stern and firm strength to the lipid bilayer of liposomes due to which it is considered as relatively more rigid compared with elastic liposomes [28]. The result of elasticity of all elastic liposomes and liposomes is portrayed in Figure 5B. Total twelve elastic liposomes loaded with LUT were prepared (LEL1-LEL12) as per suggested block (Table 2). All of the elastic liposome formulations exhibited significantly $(p<0.05)$ higher elasticity (in the range of $20.6 \pm 1.0-35.5 \pm 1.3$ ) as compared with liposomes $(E=18.3 \pm 0.7)$ (Figure $5 \mathrm{~B}$ ). There was a remarkable impact of Span 80 concentration relative to PC for elasticity. LEL1, LEL5, LEL10, and LEL11 exhibited higher elasticity among them which may be attributed to high content of Span $80(30 \mathrm{mg}$ ) as compared with others. Likewise, LEL3, LEL6, LEL8, and LEL12 revealed relatively low elasticity as evidenced by a low content of Span $80(5 \mathrm{mg})$. Formulations LEL2, LEL4, LEL7, and LEL9 exhibited elasticity in the range of 20-23.7. This may be attributed to cholesterol free vesicular lipid bilayer and ethanol mediated fluidity imparted to the layer. There are several factors controlling the elasticity of lipid vesicles such as composition, hydrocarbon chain of lipid, types of edge activator, polarity of head group of lipid and surfactant, glass transition temperature of lipid, and glycerol bridge as link of acyl hydrocarbon [29]. Moreover, molecular weight, degree of unsaturation in hydrocarbon, cholesterol content, transition temperature, and the nature of surfactant all have a collective influence in modulating the fluidity and flexibility of the lipid bilayer of the vesicle's system for enhanced permeation across the microscopic pores of human skin [28]. 

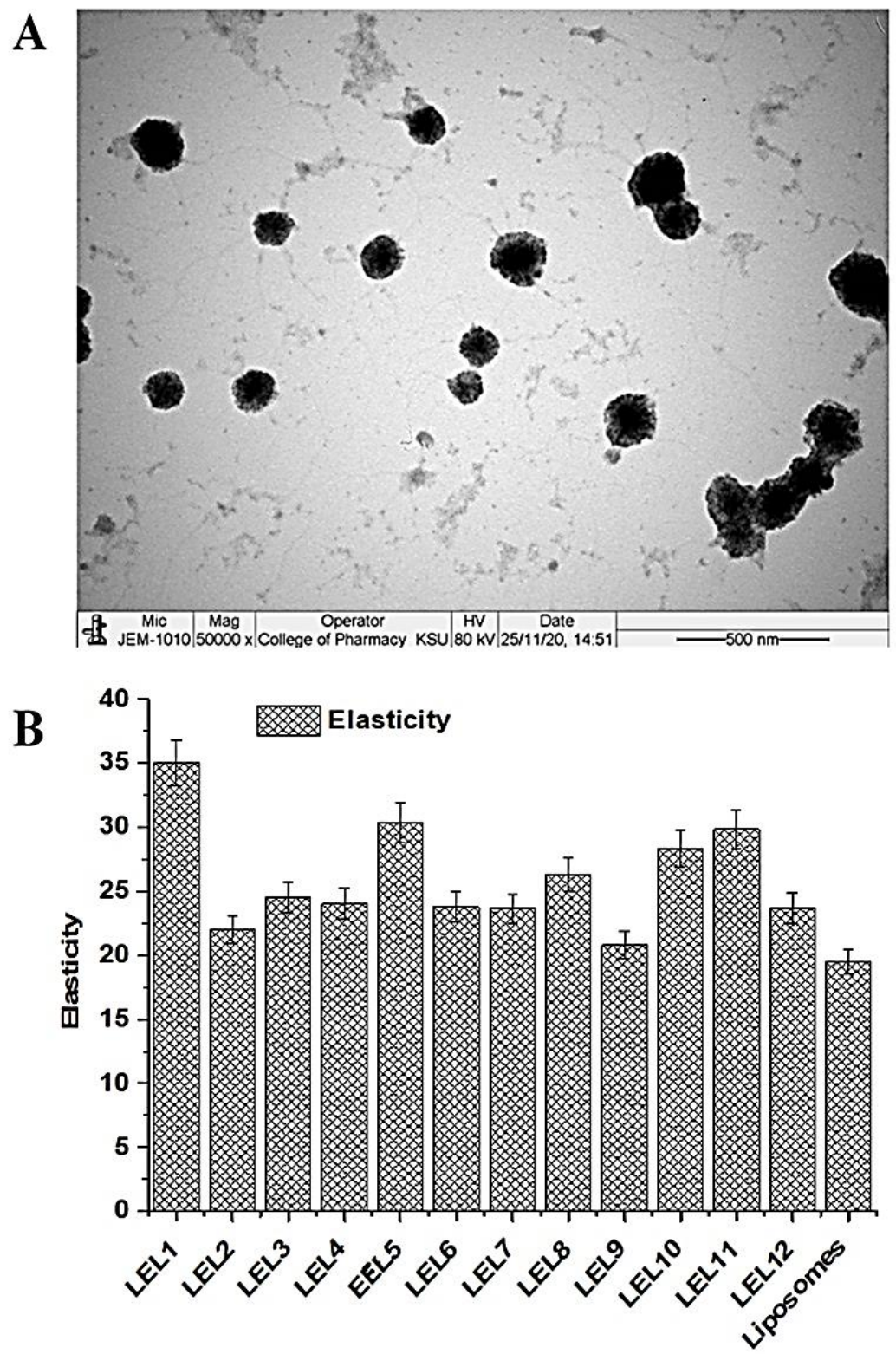

Figure 5. (A) Morphological study of OLEL1, using TEM, (B) elasticity of developed LUT-loaded elastic liposomes (LEL1-LEL12) and comparison against liposomes.

\subsubsection{In Vitro Drug Release Study}

The percentage of LUT released over $12 \mathrm{~h}$ for OLEL1, lipo, and DS are depicted in Figure 6. OLEL1 exhibited maximum release over period of $12 \mathrm{~h}$ which was attributed to the optimum content of $X_{1}(P C=70 \mathrm{mg})$ and $X_{2}$ (Span $\left.80=30 \mathrm{mg}\right)$. In the first two hours there were no significant differences between OLEL1 and lipo in LUT release. Moreover, OLEL1 exhibited a slow and sustained release over the experimental time period with a maximum released at $12 \mathrm{~h}$ of $\sim 56 \%$. However, both lipo and DS showed only $\sim 27 \%$ and $\sim 11 \%$ at $12 \mathrm{~h}$, respectively. In a previous report, Abidin et al. claimed approximately $80 \%$ LUT release from control gel within $12 \mathrm{~h}$ which was due to ethanolic solution of LUT [14]. In the present study, DS exhibited a limited release of the drug over a period of $12 \mathrm{~h}$ which is due to the poor aqueous solubility of LUT at the studied temperature. However, improved release of the drug from the elastic liposome may be prudent to correlate with increased solubilization of LUT in the lipid bilayer of the vesicle, subsequently resulting in a slow and sustained release behavior. Controlled release may be attributed to the lipid bilayer serving as a rate limiting membrane. Comparing with liposomes, liposomes exhibited a 
2.07-fold slower release than OLEL1 due to cholesterol-based rigid vesicle [28]. Flavonoid loaded liposomes are challenged with physical stability and drug leakage after long term storage. This stability depends upon the orientation of the flavonoid (LUT) in the lipid bilayer membrane of liposomes involving lipophilicity, and planar geometry [15]. These two properties resulted in a decreased permeability of the lipid bilayer membrane, a high affinity of LUT to liposomes, and a rigidifying role on the membrane [30,31].

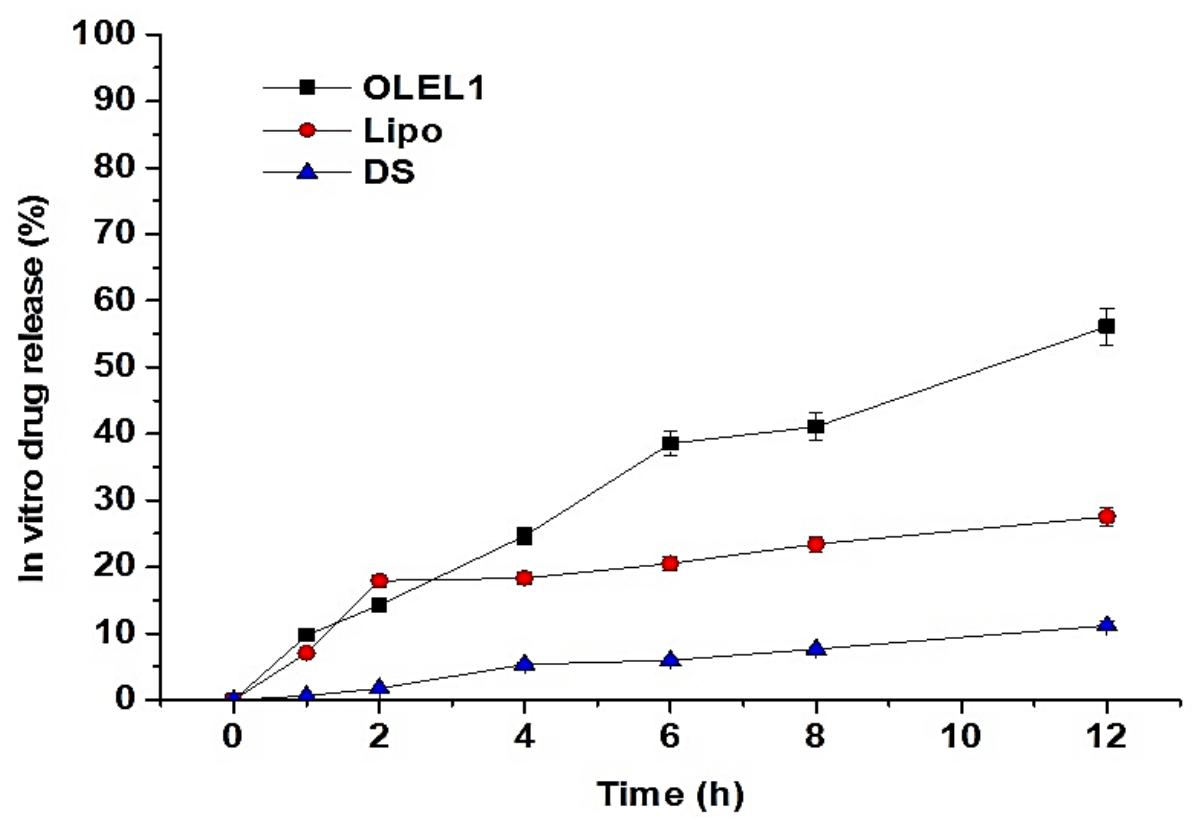

Figure 6. In vitro drug release pattern of the optimized elastic liposome formulations (OLEL1) as compared with conventional liposome (lipo) and drug solution (DS) over period of $12 \mathrm{~h}$. OLEL1 and lipo showed significant difference $(p<0.05)$. Data presented are mean $\pm \operatorname{s.d}(n=2)$.

\subsubsection{Ex Vivo Permeation and DD Studies across Rat Skin}

Permeation behavior of several drugs across human skin remained a challenging task due to the unique physiological feature of stratum corneum (SC) as a critical barrier [32]. In this study, an LUT vesicle-based approach was utilized for transdermal delivery using rat skin over $24 \mathrm{~h}$ (Figure 7A). Optimized formulations for OLEL1 and lipo showed permeation values of $\sim 3270 \mu \mathrm{g} / \mathrm{cm}^{2}$ and $\sim 1536 \mu \mathrm{g} / \mathrm{cm}^{2}$ across rat skin at $24 \mathrm{~h}$, respectively. This demonstrated a 6.2- and 2.9-fold increase over DS. The OLEL1 release rate was expected to be controlled by the lipid bilayer as the controlling factor, with the SC layer as the main rate-controlling physiological factor [32]. This is associated with the hydrophobic nature of the drug and its likely compatibility with the hydrophobic SC layer of the skin. In addition, LUT-loaded OLEL1 exhibited significant permeation which may be due to the small size of the vesicles, high drug entrapment, and profound fluidity in elastic liposomes as compared with other liposomes. Span 80 is associated with the unsaturation in long chain hydrocarbons of oleate ester (presence of double bond) which causes a disturbance in the packing chain of the edge activator. This disturbed packing in the lipid bilayer results in increased fluidity, flexibility in the lipid bilayer, elasticity, and ease of squeezing across SC and microscopic pores [33]. This suggested that the encapsulated LUT was successfully permeated through the epidermis using mechanisms such as deformability, squeezing solubility in skin lipid, and hydration effect [23]. Furthermore, the rat skin permeation flux values of OLEL1, and lipo were found to be $136.3,64$ and $24.3 \mu \mathrm{g} / \mathrm{h} / \mathrm{cm}^{2}$, respectively (Table 5). The calculated values of enhancement ratio for OLEL1 and lipo were 5.6 and 2.6, respectively. These results are in agreement with the published report of LUT-loaded niosomal gel wherein the enhancement ratio achieved was 2.66, similar to the liposome-based product in our case [14]. In contrast, the optimized OLEL1 achieved a 1.5 times higher permeation flux value as compared with the published niosomal LUT 
$\left(93.21 \mu \mathrm{g} / \mathrm{h} / \mathrm{cm}^{2}\right)$ across skin [14]. The lag time was, also, significantly lower for OLEL1 (2 h) compared with lipo and DS, at 4.5 and 4 , respectively.
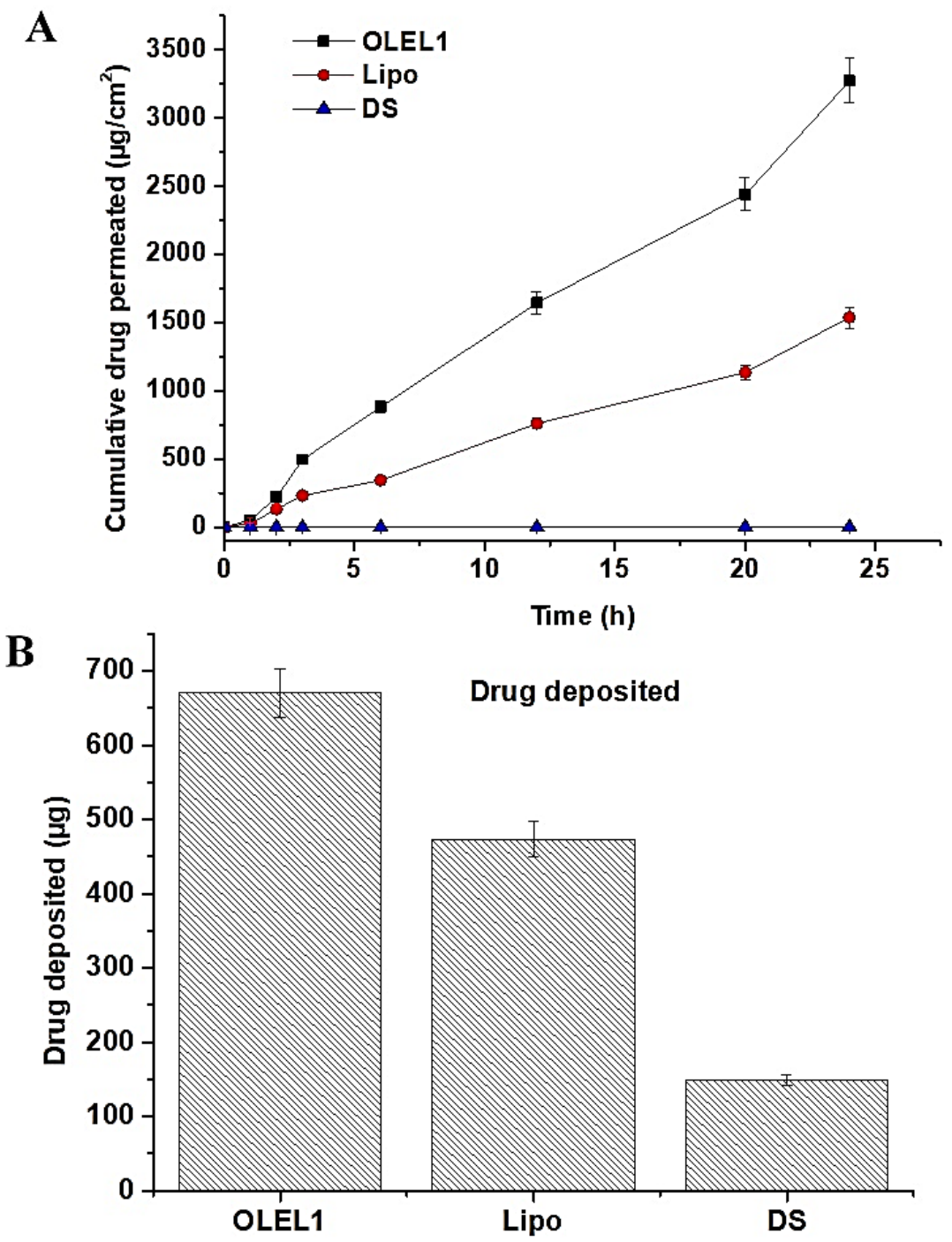

Figure 7. (A) Ex vivo LUT release pattern of the optimized elastic liposomes formulations (OLEL1) as compared with conventional liposome (lipo) and drug solution (DS) over a period of $24 \mathrm{~h}$. Data presented are mean \pm s.d $(n=2)$, and (B) drug deposition study of OLEL1, lipo and DS into the skin after $24 \mathrm{~h}$ of permeation study. Data presented are mean $\pm \operatorname{s.d}(n=2)$.

Table 5. Ex vivo permeation parameters of luteolin-loaded formulations after $24 \mathrm{~h}$.

\begin{tabular}{lllll}
\hline Formulations & $\mathbf{J s s}^{\mathbf{1}}\left(\boldsymbol{\mu g} / \mathbf{c m}^{\mathbf{2}} \mathbf{h}\right)$ & $\mathbf{T}_{\mathbf{L}}$ (mean $\left.\pm \mathbf{s d}\right)(\mathbf{m i n})$ & $\mathbf{P c}($ mean $\pm \mathbf{s d}) \mathbf{( c m} / \mathbf{h})$ & ER $^{\mathbf{1}}$ \\
\hline OLEL1 & $136.26 \pm 7.76$ & $2.0 \pm 0.01$ & $1.36 \times 10^{-2}$ & 5.61 \\
Lipo & $64.01 \pm 0.91$ & $4.5 \pm 0.03$ & $6.4 \times 10^{-3}$ & 2.63 \\
DS & $24.31 \pm 3.38$ & $4.0 \pm 0.02$ & $2.3 \times 10^{-3}$ & - \\
\hline
\end{tabular}

Value represented as mean $\pm \mathrm{SD}(n=3)$. Jss ${ }^{1}=$ transdermal flux, calculated from the slope of Cartesian plot of cumulative amount of drug present in receptor compartment versus time. $\mathrm{T}_{\mathrm{L}}=$ lag time $(\mathrm{h}) . \mathrm{P}_{\mathrm{C}}=$ permeation coefficient $=$ flux $/$ the initial concentration of rifampicin dose applied to donor compartment. ER $^{1}=$ enhancement ratio; This is the ratio of transdermal flux from the formulation to drug solution (injection solution). 
Results of the drug deposition study are presented in Figure 7B. OLEL1, lipo and DS formulation deposited LUT as $670 \mu \mathrm{g}\left(22.33 \% / \mathrm{cm}^{2}\right), 473 \mu \mathrm{g}\left(15.76 \% / \mathrm{cm}^{2}\right)$ and $148 \mu \mathrm{g}$ $\left(4.9 \% / \mathrm{cm}^{2}\right)$, respectively. It is apparent that for maximum LUT deposition higher permeation flux is needed as found in OLEL1. Moreover, OLEL1 and lipo showed 4.5- and 3.2-fold increases in drug deposition as compared with DS. In general, the more the value of drug deposition, the more permeation flux is expected due to drug deposit formation in the dermal layer. Thus, the elastic, deformability, flexibility, and fluidity behaviors of the vesicle membrane, and permeation improvement through surfactant and plasticizer of elastic liposomes, supported drug deposition and subsequent permeation flux of LUT [34].

In our recent publication, we reported cation nanoemulsion for transdermal delivery of LUT using bergamot oil (as organic phase), cremophor-EL (surfactant), labrasol (as surfactant) and oleylamine as positive charge inducer [34]. On comparing cationic nanoemulsion (CNE4) with anionic nanoemulsion, the imposed cationic charge enhanced the transdermal permeation profile across rat skin. It is interesting that the elastic liposomebased formulation achieved the same permeation flux $\left(136.3 \mu \mathrm{g} / \mathrm{cm}^{2} \mathrm{~h}\right)$ without this charge imposed on the vesicle surface or cationic lipid. However, the optimized elastic liposome "OLEL1" was found to have a higher drug deposition value $\left(22.33 \% / \mathrm{cm}^{2}\right)$ as compared with the previously reported cationic CNE-4 $\left(10.98 \% / \mathrm{cm}^{2}\right)$ [34]. Thus, the augmented flux and drug deposition of LUT may be attributed to the ultra-deformability and flexibility of elastic liposomes (free from cholesterol content) as compared with cholesterol based liposomes. In addition, it may be prudent to correlate the high drug deposition of OLEL1's vesicular nature and high drug entrapment as compared with cationic nanoemulsion.

\subsubsection{Cytotoxicity Study}

Data reveal that both LUT standard and LUT formulation exhibit concentration dependent effects on the cell viability of MCF7. Cell viability (\%) for different LUT standard concentrations was $118.95 \pm 5.09(6.69 \mu \mathrm{M}), 93.64 \pm 2.37(13.38 \mu \mathrm{M}, p<0.05), 86.4 \pm 3.0$ (26.75 $\mu \mathrm{M}, p<0.005), 78.22 \pm 0.52(53.5 \mu \mathrm{M}, p<0.005), 69.94 \pm 4.47(107.5 \mu \mathrm{M}, p<0.005)$ and $56.0 \pm 2.45(215 \mu \mathrm{M}, p<0.005)$. Cell viability (\%) for different concentrations of LUT formulation was $103.09 \pm 1.9(6.69 \mu \mathrm{M}),, 66.81 \pm 7.44(13.38 \mu \mathrm{M}, p<0.05), 64.28 \pm 5.91$ $(26.75 \mu \mathrm{M}, p<0.005), 54.81 \pm 3.34(53.5 \mu \mathrm{M}, p<0.005), 50.05 \pm 3.91(107.5 \mu \mathrm{M}, p<0.005)$ and $49.6 \pm 2.91(215 \mu \mathrm{M}, p<0.005)$. On comparing the same concentration groups in both, the LUT formulation exhibited significantly higher efficiency against MCF7 cell viability as compared with LUT standard $(p<0.001)$, except in the $215 \mu \mathrm{M}$ concentration group. When comparing the effects, it clearly appears that the formulation of LUT has enhanced growth inhibitory effects in MCF7 cells (Figure 8). In the present investigation, the $\mathrm{IC}_{50}$ of the LUT standard in MCF7 cells was found to be $216.81 \mu \mathrm{M}$, which is reduced by the formulation to $164.4 \mu \mathrm{M}$ that is 1.31 times lower than standard LUT, something which may be due to the short incubation time $(4 \mathrm{~h})$. MTT assay, or cell viability assay, revealed that the LUT has concentration dependent inhibitory effects on the growth of MCF7 cells. These effects indicate the cytotoxic nature of the LUT against cancer cells in vitro and can be exploited for further investigation. Data from the cell viability assay also highlighted that the LUT-containing formulation has significantly enhanced these effects in terms of reducing the $\mathrm{IC}_{50}$ as compared with standard LUT. The blank formulation did not show any cytotoxicity against MCF-7 cells which may be due to biocompatibility regarding the phospholipid and nonionic surfactant. In the present study, the cytotoxicity behavior of LUT was investigated for short incubation time (30 min). However, the formulation illustrated a rapid reduction in viable cells after treatment as compared with pure drugs. For further advancement in the current work, we need to investigate concentration- and incubation time-dependent cellular inhibition (antitumor potential) against the same cell lines. Jeon and Suh investigated the synergistic antiapoptotic effect of celecoxib and LUT on breast cancer cells followed by varied incubation time against the same cell lines [35]. 


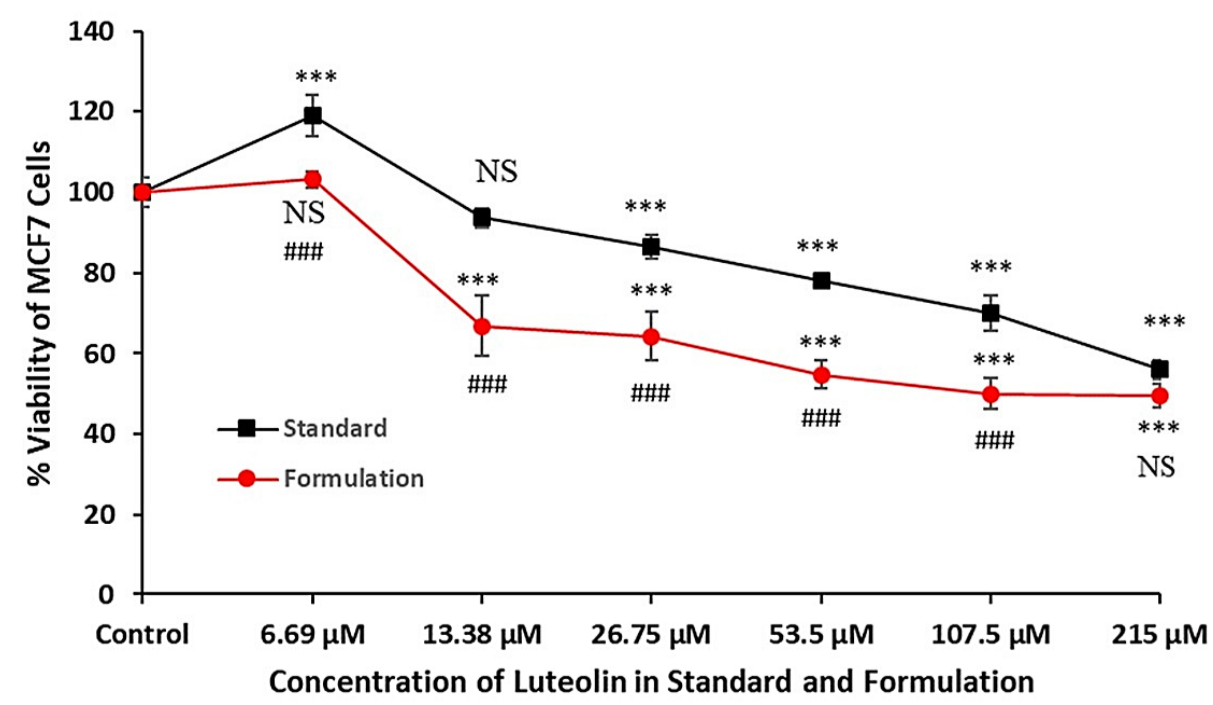

Figure 8. Effect of different concentrations of luteolin standard and luteolin formulation (OLEL1) on viability of MCF7 cells evaluated by MTT assay. Data are presented in percent (\%) in comparison with control as $100 \%$. Tukey test was utilized to analyze statistically significant difference between different concentration exposures and control. Difference was considered significant if $p$ value was found to be $<0.05$. NS = not significant when compared with control; ${ }^{* * *}=p<0.001$ when compared with control; NS = not significant when compared with same concentration group of luteolin standard; $\# \#=p<0.001$ when compared with same concentration group of luteolin standard.

\section{Materials and Methods}

\subsection{Materials}

Luteolin (LUT) was purchased from Beijing Mesochem Technology Co. Pvt. Ltd. (Beijing, China). Phospholipon ${ }^{\circledR}$ 90G (P-90G) (GmbH, Nattermannallee 1, Koln, Germany) is chemically phosphatidylcholine (PC) containing ascorbyl palmitate (0.1\%). Span 60, Span 80 and Brij 35 were procured from Thermo-Fisher Scientific (Waltam, MA, USA). DMSO (VWR Chemicals, France), MTT (3-(4,5-Dimethylthiazol-2-yl)-2,5-Diphenyltetrazolium Bromide) (Invitrogen, Thermo Fisher, USA), Advanced DMEM (Dulbecco's Modified Eagle Medium) (Gibco, Life Technologies Ltd., London, UK), $\mathrm{NaCl}$ (sodium chloride), $\mathrm{KCl}$ (potassium chloride), $\mathrm{Na}_{2} \mathrm{HPO}_{4}$ (disodium hydrogen phosphate) and $\mathrm{KH}_{2} \mathrm{PO}_{4}$ (potassium dihydrogen phosphate) were procured from Scharlab S.L., Barcelona, Spain. Millipore water was used as an aqueous medium.

\subsection{Preparation of Luteolin-Loaded Elastic Liposomes (LELs) Using Various Surfactants}

The elastic liposomes (ELs) were formulated using a rotary evaporation technique (RET) [13]. PC and surfactants were first dissolved in a mixture of methanol-chloroform (1:2 ratio). Formulations were prepared using different surfactants namely Span 60 (F1, F2, F3), Span 80 (F4, F5, F6) and Brij 35 (F7, F8, F9) with different PC to surfactant ratios. The selected ratio 95:5, 85:15 and 70:30 were applied for each surfactant. Briefly, precisely weighed excipients and the drug $(30 \mathrm{mg})$ was completely dissolved in a round bottom flask (RBF) containing methanol-chloroform mixture (1:2) (3 mL). The RBF went under evaporation of moderate temperature $\left(40 \pm 2{ }^{\circ} \mathrm{C}\right)$ and reduced pressure leading to a thin film (on inner surface). The film was hydrated with hydro alcoholic $(0.7 \% v / v$ ethanol as plasticizer) PBS (10 mL, pH 5.5) solution. Thus, obtained colloidal milky elastic liposome formulations were sonicated (60 s) to reduce vesicle size [29,36,37]. Eventually, these were preserved in a freezer to activate vesicles $(12 \mathrm{~h})$. Each $\mathrm{g}$ of formulation contains $3 \mathrm{mg}$ of LUT $(0.3 \% w / w)$. 


\subsection{Vesicle Size and Size Distribution (Polydispersity Index, PDI)}

Each formulation was individually assessed for size and PDI using a Zetasizer Nano ZS (Malvern Instruments, Worcestershire, UK) equipped with $4.0 \mathrm{~mW} \mathrm{He} \mathrm{Ne}$ red laser $(633 \mathrm{~nm})$ [37]. The samples were previously diluted (100 times) using water (milli-Q) to avoid instrument al error during analysis. The experiment was performed at $25 \pm 1{ }^{\circ} \mathrm{C}$ and scattering angle of $90^{\circ}$.

\subsection{Experimental Design Tool (Design Expert ${ }^{\circledR}$ )}

Finding the optimum content of excipients in a formulation is called optimization. Therefore, Design-Expert 13.0.5 software was used to design the experiment (Table 2). Two blocks factorial design with four center points (12 runs) was employed to explore the design space for the selected factors and responses. This would later allow the software to predict the optimized formulation(s). This "Design Expert software" follows a random order for desired combination(s) to maximize the chance of identifying variation between runs. In this study, PC $\left(X_{1}\right)$ and Span $80\left(X_{2}\right)$ were selected as independent factors (variables) against four dependent variables. These responses were vesicle size $\left(\mathrm{Y}_{1}\right)$, Zeta potential $\left(\mathrm{Y}_{2}\right)$, and $\% \mathrm{EE}\left(\mathrm{Y}_{3}\right)$. Both dependent and independent variables values are shown in Table 2. Smaller size liposomal formulations have a better chance to pass through the microscopic pores of the skin due to high elasticity. However, an optimum concentration of excipient is opted for safety concern and maximized delivery of LUT $(0.05 \% w / w)$. Hence, two levels of PC were selected as $70 \mathrm{mg}$ (low) and $95 \mathrm{mg}$ (high) whereas Span 80 was set at $5 \mathrm{mg}$ (low) and $30 \mathrm{mg}$ (high).

In addition, the regression equation showing the best fit using the selected mathematical models was used and validated by equating various statistical parameters such as $p$ value, regular, adjusted and predicted correlation coefficient $\left(r^{2}\right)[38,39]$. Polynomial equations generated 3-dimensional surface and contour graphs were produced by the software. $p$ and $F$ values were used to assess model suitability while the optimization process was assessed using individual $\left(d_{i}\right)$ and overall desirability function $\left(\mathrm{D}_{\mathrm{i}}\right)$. Table 3 summarizes details of independent $\left(X_{1}\right.$ and $\left.X_{2}\right)$ and dependent variables $\left(Y_{1}\right.$ to $\left.Y_{3}\right)$. This value depends on several independent variables and set goals.

\subsection{Formulations Characterizations}

\subsubsection{Vesicle Size and Zeta Potential}

All prepared formulations were prepared and evaluated for size, polydispersity index (PDI) and surface charge (zeta potential, $\mathrm{mV}$ ). Vesicle size and size distribution were assessed as per method reported in previous section. All of the formulations were assessed for zeta potential as an essential parameter controlling stability of the product. The sample was diluted (100 times) with water to disperse vesicles in the medium before size and PDI determination. In case of zeta analysis, the liposomal colloid was processed as such without dilution.

\subsubsection{Percentage Entrapment Efficiency (\% EE)}

This was determined by the reported procedure [40,41]. Developed formulations were placed aside overnight at $4{ }^{\circ} \mathrm{C}$. Un-entrapped (free drug) was determined using Eppendorf tube $(2 \mathrm{~mL})$ centrifugation method $(15,000 \mathrm{rpm}$ for $15 \mathrm{~min})$. The procedure was repeated to remove free drug completely. LUT contents were determined using a HPLC technique at $\lambda_{\max }$ of $350 \mathrm{~nm}$. Finally, the entrapped drug in the vesicles was calculated by Equation (1):

$$
\left.\% \mathrm{EE}=\left[\left(\mathrm{Q}_{\mathrm{t}}-\mathrm{Q}_{\mathrm{s}}\right) / \mathrm{Q}_{\mathrm{t}}\right)\right] \times 100
$$

where, " $\mathrm{Q}_{\mathrm{t}}$ " and " $\mathrm{Q}_{\mathrm{s}}$ " were the added theoretical content of the drug added and the content of LUT present in the clear supernatant, respectively. 


\subsubsection{Desirability Function Parameter and Validation}

Desirability is a numerical function with the objective to reach the value of 1 leading to the best fit within expected constraints and goals. This is, also, used to identify interaction between factors if it exists. Statistically, "Di" is a geometrical mean function of the explored responses depending upon set "maximum", "minimum", "in range" "equal to", and "target" ranges by the investigator during optimization process (Equation (2)):

$$
\left.\mathrm{D}_{\mathrm{i}}=\left(d_{1} \cdot d_{2} \ldots d_{n}\right)=\mathrm{II}_{\mathrm{ii}=1} d_{i}\right)^{1 / \mathrm{n}}
$$

\subsubsection{Morphological Assessment}

The formulation with highest desirability value (OLEL1) was visualized under transmission electron microscopy (TEM) (JOEL JEM1010, Japan). The sample (2-3 drops) was kept on a glass coverslip and dried overnight. Then, the same sample was kept on the carbon-coated copper grid for complete drying. Osmium was used to stain the lipid components and left for $24 \mathrm{~h}$ to dry. Then, the sample was loaded into the TEM to be viewed under different magnifications.

\subsubsection{Elasticity}

Elasticity was measured following the reported method [42-44]. Briefly, elastic liposomes (LEL1-LEL12) and liposomes (as control) were extruded through a $50 \mathrm{~nm}$ pore-sized membrane $\left(\mathrm{r}_{\mathrm{p}}\right)$ for 10 min under 2.5 bar pressure. The extruded volume $(\mathrm{J})$ and the mean diameter of the vesicles after extrusion $\left(r_{v}\right)$ were determined. Thus, the elasticity $(E)$ of vesicles was calculated using Equation (3):

$$
\mathrm{E}=J \times\left(\mathrm{r}_{\mathrm{v}} / \mathrm{r}_{\mathrm{p}}\right)^{2}
$$

\subsubsection{In Vitro Drug Release (\%DR)}

OLEL1, control liposome (lipo) and drug suspension (DS) prepared using $0.1 \% w / v$ sodium CMC (Na-carboxymethyl cellulose), were studied to understand their \%DR profile. The study was conducted using a dialysis membrane (molecular cut-off 12-14 KDa, Himedia Labs). Each formulation and control samples ( $2 \mathrm{~mL}$ containing $6 \mathrm{mg}$ LUT) were separately placed in the membrane tied from each ends using clip. The sample containing membrane bag was suspended in a beaker previously filled with $400 \mathrm{~mL}$ of PBS (pH 7.4) set at $37 \pm 1{ }^{\circ} \mathrm{C}$ and constant stirring (100 rpm) using magnetic bead. The sample for analysis ( $3 \mathrm{~mL}$ ) was withdrawn at $1,2,4,6,8$, and $12 \mathrm{~h}$ to estimate the drug concentration released in the medium using a U.V. spectrophotometer at $350 \mathrm{~nm}$.

\subsection{Analytical Method}

The quantitative assessment of LUT was performed using a validated high performance liquid chromatography (HPLC) technique [45]. In this, the packing material of the analytical column $(150 \mathrm{~mm} \times 4.5 \mathrm{~mm})$ worked as stationary phase with particle size of $5 \mu \mathrm{m}$ operating at $30 \pm 1{ }^{\circ} \mathrm{C}$. The sample was injected at low volume $(20 \mu \mathrm{L}$ ) for $8 \mathrm{~min}$ (run time) at flow rate of $1 \mathrm{~mL} / \mathrm{min}$. For quantitative assessment, the mobile phase (MP) was freshly prepared using acetonitrile, methyl alcohol, and aqueous (including $1 \% v / v$ acetic acid). These components were prepared in 60:30:10\% $v / v$, ratio. The prepared MP was set at $\mathrm{pH} 4.0$ and subsequently passed through a membrane filter to retain any fibers and particles (if found). The drug analysis was conducted on an isocratic mode using a UV detector (350 $\mathrm{nm}$ as set wavelength). A working calibration curve was constructed over concentration range of $20-100 \mu \mathrm{g} / \mathrm{mL}$ with high regression coefficient $\left(\mathrm{r}^{2}>0.99\right)$ [45].

\subsection{Ex Vivo Drug Permeation and Deposition Study}

This study was carried out using rat skin (excised from abdominal portion) (body weight of $\sim 200 \mathrm{~g}$ albino male rats) from the Animal Center, College of Pharmacy, King Saud University, Riyadh, Saudi Arabia. Approval (2 December 2020) was issued from 
the Institute's Ethics Committee (King Saud University, Riyadh) (KSU-SE-20-64). This experiment was conducted based on the guideline for animal care (NC3Rs, ARRIVE guidelines). Stratum corneum (SC) of rat skin has similar thickness to human skin and shows similarity in the permeation in different studies [46]. Thus, transdermal permeation of the optimized formulations (OLEL1), control liposome (lipo) and drug solution (DS) was conducted using a Franz diffusion cell. The collected skin was cleaned (free from hairs, and fatty matters) using an electric shaver. The skin was placed between both chambers where dermal side faced the receptor PBS medium ( $\mathrm{pH}$ 7.4) and donor received the sample $(\mathrm{LUT}=15 \mathrm{mg}$ ). The receptor medium was under regular stirring (rice bead, $100 \mathrm{rpm}$ ) and temperature of $37 \pm 1{ }^{\circ} \mathrm{C}$. Furthermore, sampling was carried out at 1, 2, 3, 6, 12, 20 and $24 \mathrm{~h}$ and estimated using HPLC (absorbance wavelength as $350 \mathrm{~nm}$ ). Permeation flux, cumulative permeation, and drug deposition (DD) were calculated $[28,47,48]$. DD values were obtained after completion of ex vivo permeation ( $24 \mathrm{~h}$ ). For this, the remaining sample on the surface was washed with running water and then sliced into small pieces. The drug was extracted using methanol: chloroform (1:2) mixture under constant stirring for $4 \mathrm{~h}$. The tissue was filtered and the filtrate was analyzed for the drug content [49-52].

\subsection{Cytotoxicity Study Using MCF-7 Cell Lines}

Effect on MCF7 cell viability of different concentrations of LUT standard and formulation was estimated by the MTT (3-(4,5-dimethylthiazol-2-yl)-2,5-diphenyl tetrazolium bromide). Then, MCF7 cell-lines (15,000 cells per well), were transferred to seed into the plates (96-well-oplates) along with $100 \mu \mathrm{L}$ of the culture media (DMEM, 10\% FBS). The same plates were required to incubate for overnight at $37 \pm 1{ }^{\circ} \mathrm{C}$ and constant supply of $5 \% \mathrm{CO}_{2}$ for complete adherence. To expose the cells to the compound, varied contents of LUT standard and the optimized formulation were poured into the respective wells. Standard LUT solution and formulation were prepared in DMSO (1\%) and serially diluted using serum free media in a 96-well plate. The same concentration of DMSO was used in the vehicle control to avoid cell damage. The selected the drug concentrations in standard and formulation, were $215 \mu \mathrm{M}, 107.5 \mu \mathrm{M}, 53.5 \mu \mathrm{M}, 26.75 \mu \mathrm{M}, 13.38 \mu \mathrm{M}$ and $6.69 \mu \mathrm{M}$. Cells were exposed to the samples $(24 \mathrm{~h})$, and then MTT solution $(10 \mu \mathrm{L}, 5 \mathrm{mg} / \mathrm{mL}$ PBS) was transferred to the respective wells. Furthermore, the culture was again incubated $(4 \mathrm{~h})$ so that the viable cells can metabolize MTT. The culture media was removed from each well followed by addition of DMSO solution $(100 \mu \mathrm{L})$ to solubilize the formazan of MTT. Each plate was subjected for reading after $30 \mathrm{~min}$ of incubation at $570 \mathrm{~nm}$. The DMSO solution was used as the blank.

\subsection{Statistical Analysis}

Experiments were performed in triplicate to get mean and standard deviation. All data were processed using Origin-pro (OriginLab Corporation, Northampton, MA, USA), and GraphPad version 5.01 software (La Jolla, CA, USA). Data were processed statistically using ANOVA (analysis of variance), Student's $t$-test and a Turkey or Dunnett tests (Sigma Stat Software, 2.03, San Jose, CA, USA). The value was considered significant at $p$ value of $\leq 0.05$ for fitting the applied model followed by the correlation factor $\left(\mathrm{r}^{2}\right)$.

\section{Conclusions}

The drug is challenging for formulation scientists due to low aqueous solubility, and poor oral bioavailability. Despite these limitations, the drug is well reported to have multiple therapeutic benefits, including for breast cancer (as discussed in the introduction section). Several scientists have applied techniques and carriers for improved efficacy of the drug to control breast cancer. However, no one has reported the use of vesicular elastic liposomes for transdermal delivery of LUT with improved efficacy against MCF-7 cell lines. The present study developed and optimized elastic liposomes and evaluated them for in vitro and ex vivo parameters. Results show that Span 80 was the most suitable edge activator amongst investigated surfactants (Span 60, and Brij) which may be due to 
negative glass transition temperature. Considering this, several formulations were dictated in Design Expert and characterized for vesicle size, zeta potential and \%EE. Interestingly, these results were close to the predicted values suggesting the suitability of the model adopted for optimization (desirability 0.95). TEM corroborated quite dispersed vesicles in colloidal system. Elastic liposomes showed Span 80 mediated elasticity. The optimized formulation illustrated facilitated drug release as compared with DS and rigid liposome. The proposed deformable vesicular carrier enhanced permeation parameters across rat skin as compared with DS and liposomes. Finally, the drug loaded carrier (OLEL1) exhibited concentration-dependent MCF-7 cells inhibition and elastic liposome improved cellular internalization for maximized inhibition as compared with control pure drug solution. Thus, the elastic liposomes can be a promising approach for improved transdermal delivery of LUT and enhanced therapeutic efficacy to control breast cancer.

Author Contributions: M.A.A.: funding and conceptualization; A.H.: methodology, analysis, drafting and writing; M.A.: methodology, data curation: S.A.: formal review: S.S.I.: formal review; W.Q.: analysis. All authors have read and agreed to the published version of the manuscript.

Funding: Authors thank and extend sincere appreciations to the Deanship of Scientific Research at King Saud University for their support of the present research work through research group project number RG-1441-010.

Institutional Review Board Statement: The study was conducted according to the guidelines of the Declaration of Helsinki and approved (approved on 2 December 2020) by the Institutional Review Board (or Ethics Committee) of College of Pharmacy, King Saud University (Institutional Animal House (Institutional ethical committee), Riyadh (approved ethical No: KSU-SE-20-64). The protocol was followed as per ARRIVE guidelines.

Informed Consent Statement: Not applicable.

Data Availability Statement: Not applicable.

Acknowledgments: The authors extend their appreciation to the Deanship of Scientific Research at King Saud University for funding this work through research group number RG-1441-010.

Conflicts of Interest: The authors declare no conflict of interest.

\section{References}

1. Ali, I.; Wani, W.A.; Saleem, K. Cancer scenario in India with future perspectives. Cancer Ther. 2011, 8, 56-70.

2. Jain, A.S.; Dhawan, V.K.; Sarmento, B.; Nagarsenker, M.S. In vitro and ex vivo evaluations of lipid anti-cancer nanoformulations: Insights and assessment of bioavailability enhancement. AAPS PharmSciTech 2016, 17, 553-571.

3. Sung, H.; Ferlay, J.; Siegel, R.L.; Laversanne, M.; Soerjomataram, I.; Jemal, A.; Bray, F. Global Cancer Statistics 2020: GLOBOCAN Estimates of Incidence and Mortality Worldwide for 36 Cancers in 185 Countries. CA A Cancer J. Clin. 2021, 71, 209-249. [CrossRef]

4. World Health Organization. Fact. Sheet Datail of Breast Cancer. Available online: https://www.who.int/news-room/fact-sheets/ detail/breast-cancer (accessed on 22 June 2021).

5. Seelinger, G.I.; Merfort Schempp, C.M. Anti-oxidant, anti-inflammatory and anti-allergic activities of luteolin. Planta Medica 2008, 74, 1667-1677. [CrossRef]

6. Peng, B.; Yan, W. Solubility of Luteolin in Ethanol + Water Mixed Solvents at Different Temperatures. J. Chem. Eng. Data 2010, 55, 583-585. [CrossRef]

7. Lin, Y.; Shi, R.; Wang, X.; Shen, H.-M. Luteolin, a Flavonoid with Potential for Cancer Prevention and Therapy. Curr. Cancer Drug Targets 2008, 8, 634-646. [CrossRef] [PubMed]

8. Dirscherl, K.; Karlstetter, M.; Ebert, S.; Kraus, D.; Hlawatsch, J.; Walczak, Y.; Moehle, C.; Fuchshofer, R.; Langmann, T. Luteolin triggers global changes in the microglial transcriptome leading to a unique anti-inflammatory and neuroprotective phenotype. $J$. Neuroinflamm. 2010, 7, 1-16. [CrossRef] [PubMed]

9. Süzgeç-Selçuk, S.; Birteksöz, A. Flavonoids of Helichrysum chasmolycicum and its antioxidant and antimicrobial activities. South Afr. J. Bot. 2011, 77, 170-174. [CrossRef]

10. Wu, G.; Li, J.; Yue, J.; Zhang, S.; Yunusi, K. Liposome encapsulated luteolin showed enhanced antitumor efficacy to colorectal carcinoma. Mol. Med. Rep. 2018, 17, 2456-2464. [CrossRef]

11. Chen, Z.; Tu, M.; Sun, S.; Kong, S.; Wang, Y.; Ye, J.; Li, L.; Zeng, S.; Jiang, H. The Exposure of Luteolin Is Much Lower than That of Apigenin in Oral Administration of Flos Chrysanthemi Extract to Rats. Drug Metab. Pharmacokinet. 2012, 27, 162-168. [CrossRef]

12. Dang, H.; Meng, M.H.W.; Zhao, H.; Iqbal, J.; Dai, R.; Deng, Y.; Lv, F. Luteolin-loaded solid lipid nanoparticles synthesis, characterization, \& improvement of bioavailability, pharmacokinetics in vitro and vivo studies. J. Nanoparticle Res. 2014, 16, 1-10. 
13. Trotta, M.; Peira, E.; Debernardi, F.; Gallarate, M. Elastic liposomes for skin delivery of dipotassium glycyrrhizinate. Int. J. Pharm. 2002, 241, 319-327. [CrossRef]

14. Abidin, L.; Mujeeb, M.; Imam, S.S.; Aqil, M.; Khurana, D. Enhanced transdermal delivery of luteolin via non-ionic surfactant-based vesicle: Quality evaluation and anti-arthritic assessment. Drug Deliv. 2016, 23, 1069-1074. [CrossRef] [PubMed]

15. Huang, M.; Su, E.; Zheng, F.; Tan, C. Encapsulation of flavonoids in liposomal delivery systems: The case of quercetin, kaempferol and luteolin. Food Funct. 2017, 8, 3198-3208. [CrossRef]

16. Mishra, D.; Garg, M.; Dubey, V.; Jain, S.; Jain, N. Elastic Liposomes Mediated Transdermal Deliveryof an Anti-Hypertensive Agent: Propranolol Hydrochloride. J. Pharm. Sci. 2007, 96, 145-155. [CrossRef] [PubMed]

17. Lopez, O.; De La Maza, A.; Coderch, L.; López-Iglesias, C.; Wehrli, E.; Parra, J.L. Direct formation of mixed micelles in the solubilization of phospholipid liposomes by Triton X-100. FEBS Lett. 1998, 426, 314-318. [CrossRef]

18. Cevc, G.; Gebauer, D.; Stieber, J.; Schätzlein, A.; Blume, G. Ultraflexible vesicles, Transfersomes, have an extremely low pore penetration resistance and transport therapeutic amounts of insulin across the intact mammalian skin. Biochim. Et Biophys. Acta (BBA)-Biomembr. 1998, 1368, 201-215. [CrossRef]

19. Cevc, G. Lipid vesicles and other colloids as drug carriers on the skin. Adv. Drug Deliv. Rev. 2004, 56, 675-711. [CrossRef] [PubMed]

20. Fazel, M.; Daeihamed, M.; Osouli, M.; Almasi, A.; Haeri, A.; Dadashzadeh, S. Preparation, in-vitro characterization and pharmacokinetic evaluation of Brij decorated doxorubicin liposomes as a potential nanocarrier for cancer therapy. IJPR 2018, 17, 33-43. [CrossRef]

21. Ghosh, S.; Moulik, S. Interfacial and Micellization Behaviors of Binary and Ternary Mixtures of Amphiphiles (Tween-20, Brij-35, and Sodium Dodecyl Sulfate) in Aqueous Medium. J. Colloid Interface Sci. 1998, 208, 357-366. [CrossRef]

22. Sharma, B.; Rakshit, A.K. Thermodynamics of micellization of a nonionic surfactant: Brij 35 in aquo-sucrose solution. J. Colloid Interface Sci. 1989, 129, 139-144. [CrossRef]

23. Jain, S.K.; Gupta, Y.; Jain, A.; Rai, K. Enhanced Transdermal Delivery of Acyclovir Sodium via Elastic Liposomes. Drug Deliv. 2008, 15, 141-147. [CrossRef] [PubMed]

24. Hussain, A.; Singh, S.; Sharma, D.; Webster, T.J.; Shafaat, K.; Faruk, A. Elastic liposomes as novel carriers: Recent advances in drug delivery. Int. J. Nanomed. 2017, 12, 5087-5108. [CrossRef] [PubMed]

25. Lu, G.W.; Gao, P. Emulsions and Microemulsions for Topical and Transdermal Drug Delivery. In Handbook of Non-Invasive Drug Delivery Systems; Elsevier: Amsterdam, The Netherlands, 2010; pp. 59-94.

26. Varshosaz, J.; Pardakhty, A.; Hajhashemi, V.I.; Najafabadi, A.R. Development and physical characterization of sorbitan monoester niosomes for insulin oral delivery. Drug Deliv. 2003, 10, 251-262. [CrossRef]

27. Derringer, G.; Suich, R. Simultaneous Optimization of Several Response Variables. J. Qual. Technol. 1980, 12, 214-219. [CrossRef]

28. Tas, C.; Ozkan, Y.; Okyar, A.; Savaser, A. In vitro and ex vivo permeation studies of etodolac from hydrophilic gels and effect of terpenes as enhancers. Drug Deliv. 2007, 14, 453-459. [CrossRef]

29. Chen, J.; Lu, W.-L.; Gu, W.; Lu, S.-S.; Chen, Z.-P.; Cai, B.-C. Skin permeation behavior of elastic liposomes: Role of formulation ingredients. Expert Opin. Drug Deliv. 2013, 10, 845-856. [CrossRef]

30. Ollila, F.; Halling, K.; Vuorela, P.; Vuorela, H.; Slotte, J. Characterization of flavonoid-biomembrane interactions. Arch. Biochem. Biophys. 2002, 399, 103-108. [CrossRef]

31. Selvaraj, S.; Krishnaswamy, S.; Devashya, V.; Sethuraman, S.; Krishnan, U.M. Influence of membrane lipid composition on flavonoid-membrane interactions: Implications on their biological activity. Prog. Lipid Res. 2015, 58, 1-13. [CrossRef]

32. Hussain, A.; Samad, A.; Ramzan, M.; Ahsan, M.N.; Rehman, Z.U.; Ahmad, F. Elastic liposome-based gel for topical delivery of 5-fluorouracil: In vitro and in vivo investigation. Drug Deliv. 2016, 23, 1115-1129. [CrossRef]

33. Yeom, S.; Shin, B.S.; Han, S. An electron spin resonance study of non-ionic surfactant vesicles (niosomes). Chem. Phys. Lipids 2014, 181, 83-89. [CrossRef]

34. Cevc, G.; Blume, G.; Schätzlein, A. Transfersomes-mediated transepidermal delivery improves the regio-specificity and biological activity of corticosteroids in vivo. J. Control Release 1997, 45, 211-226. [CrossRef]

35. Jeon, Y.-W.; Suh, Y.J. Synergistic apoptotic effect of celecoxib and luteolin on breast cancer cells. Oncol. Rep. 2012, 29, 819-825. [CrossRef]

36. Ita, K.B.; Du Preez, J.; du Plessis, J.; Lane, M.E.; Hadgraft, J. Dermal delivery of selected hydrophilic drugs from elastic liposomes: Effect of phospholipid formulation and surfactants. J. Pharm. Pharmacol. 2007, 59, 1215-1222. [CrossRef] [PubMed]

37. Balaguer-Fernández, C.; Femenía-Font, A.; Merino, V.; Cordoba-Diaz, D.; Elorza-Barroeta, M.A.; López-Castellano, A.; CordobaDiaz, M. Elastic vesicles of sumatriptan succinate for transdermal administration: Characterization and in vitro permeation studies. J. Liposome Res. 2011, 21, 55-59. [CrossRef] [PubMed]

38. Gusai, T.; Dhavalkumar, M.; Soniwala, M.; Dudhat, K.; Vasoya, J.; Chavda, J. Formulation and optimization of microspongeloaded emulgel to improve the transdermal application of acyclovir-a DOE based approach. Drug Deliv. Transl. Res. 2020, 1-21. [CrossRef] [PubMed]

39. Prasanthi, D.; Lakshmi, P.K. Development of ethosomes with taguchi robust design-based studies for transdermal delivery of alfuzosin hydrochloride. Int. Curr. Pharm. J. 2012, 1, 370-375. [CrossRef]

40. Duangjit, S.; Opanasopit, P.; Rojanarata, T.; Ngawhirunpat, T. Evaluation of meloxicam-loaded cationic transfersomes as transdermal drug delivery carriers. AAPS PharmSciTech 2012, 14, 133-140. [CrossRef] 
41. Ahad, A.; Aqil, M.; Kohli, K.; Sultana, Y.; Mujeeb, M. Enhanced transdermal delivery of an anti-hypertensive agent via nanoethosomes: Statistical optimization, characterization and pharmacokinetic assessment. Int. J. Pharm. 2013, 443, 26-38. [CrossRef]

42. Mishra, D.; Dubey, V.; Asthana, A.; Saraf, D.; Jain, N. Elastic liposomes mediated transcutaneous immunization against Hepatitis B. Vaccine 2006, 24, 4847-4855. [CrossRef]

43. Benson, H.A. Elastic Liposomes for Topical and Transdermal Drug Delivery, in Liposomes; Springer: Berlin/Heidelberg, Germany, 2010; pp. 77-86.

44. Vanić, Ž.; Rukavina, Z.; Manner, S.; Fallarero, A.; Uzelac, L.; Kralj, M.; Klarić, D.A.; Bogdanov, A.; Raffai, T.; Virok, D.P.; et al. Azithromycin-liposomes as a novel approach for localized therapy of cervicovaginal bacterial infections. Int. J. Nanomed. 2019, 14, 5957-5976. [CrossRef] [PubMed]

45. Altamimi, M.A.; Hussain, A.; Alshehri, S.; Imam, S.S.; Alnemer, U.A. Develop-ment and Evaluations of Transdermally Delivered Luteolin Loaded Cationic Nanoemulsion: In Vitro and Ex Vivo Evaluations. Pharmaceutics 2021, 13, 1218. [CrossRef] [PubMed]

46. Godin, B.; Touitou, E. Transdermal skin delivery: Predictions for humans from in vivo, ex vivo and animal models. Adv. Drug Deliv. Rev. 2007, 59, 1152-1161. [CrossRef]

47. Gannu, R.; Vishnu, Y.V.; Kishan, V.; Rao, Y.M. Development of Nitrendipine Transdermal Patches: In vitro and Ex vivo Characterization. Curr. Drug Deliv. 2007, 4, 69-76. [CrossRef] [PubMed]

48. Gannu, R.; Palem, C.R.; Yamsani, V.V.; Yamsani, S.K.; Yamsani, M.R. Enhanced bioavailability of lacidipine via microemulsion based transdermal gels: Formulation optimization, ex vivo and in vivo characterization. Int. J. Pharm. 2010, 388, $231-241$. [CrossRef]

49. AbdelSamie, S.M.; Kamel, A.O.; Sammour, O.; Ibrahim, S. Terbinafine hydrochloride nanovesicular gel: In vitro characterization, ex vivo permeation and clinical investigation. Eur. J. Pharm. Sci. 2016, 88, 91-100. [CrossRef]

50. Thomas, L.; Zakir, F.; Mirza, M.A.; Anwer, K.; Ahmad, F.; Iqbal, Z. Development of Curcumin loaded chitosan polymer based nanoemulsion gel: In vitro, ex vivo evaluation and in vivo wound healing studies. Int. J. Biol. Macromol. 2017, 101, 569-579. [CrossRef]

51. Aziz, D.E.; Abdelbary, A.A.; Elassasy, A.I. Investigating superiority of novel bilosomes over niosomes in the transdermal delivery of diacerein: In vitro characterization, ex vivo permeation and in vivo skin deposition study. J. Liposome Res. 2019, 29, 73-85. [CrossRef]

52. Pandey, S.S.; Shah, K.M.; Maulvi, F.A.; Desai, D.T.; Gupta, A.R.; Joshi, S.V.; Shah, D.O. Topical delivery of cyclosporine loaded tailored niosomal nanocarriers for improved skin penetration and deposition in psoriasis: Optimization, ex vivo and animal studies. J. Drug Deliv. Sci. Technol. 2021, 63, 102441. [CrossRef] 